\title{
Pulmonary function in panic disorder: evidence against the dyspnea-fear theory
}

\author{
PH. SPINHOVEN, ${ }^{\prime *}$ E. J. ONSTEIN ${ }^{1}$ and P. J. STERK ${ }^{2}$ \\ 'Department of Psychiatry, University of Leiden, P.O. Box 125I, 2340 BG Oegstgeest and \\ ${ }^{2}$ Lung Function Laboratory, University Hospital Leiden, The Netherlands
}

(Received 24 June 1994)

\begin{abstract}
Summary-The present study addresses the hypothesis consistent with the dyspnea-fear theory of panic, that in a subgroup of panic patients a non-pathological pulmonary obstructive component may induce dyspnea, dyspneic fear and, ultimately, panic. In 38 patients who met $D S M-I I I-R$ criteria for panic disorder, pulmonary function was assessed and various measurements for panic symptoms and concomitant psychopathology were collected. In comparison to patients with a high Forced Expiratory Flow at $50 \%$ (FEF 50\%), low FEF 50\% patients demonstrated significantly lower levels of Forced Expiratory Volume (first second) and Peak Expiratory Flow and significantly lower FEV $/$ FVC ratios. None of the differences on psychological measurements for symptom severity between low and high FEF $50 \%$ patients proved to be significant. Moreover, FEF $50 \%$ scores and $\mathrm{FEV}_{1} / \mathrm{FVC}$ ratios were not correlated to any of the measures for panic or associated psychopathology. It is concluded that the existence of a distinct subgroup of panic patients with signs of actual airway obstruction leading to uncontrollable dyspnea and fear of suffocation remains questionable.
\end{abstract}

\section{INTRODUCTION}

According to Ley (1992) panic attacks according to DSM-III-R criteria (American Psychiatric Association, 1987) can be defined on the basis of physiological and psychological dimensions that fit three categories of severity: Type I (classic panic attack), Type II (anticipatory panic attack), and Type III (cognitive panic attack). The classic panic attack is characterized by uncontrollable dyspnea in conjunction with the fear of suffocation. In contrast to the cognitive model of panic (Clark, 1986) catastrophic cognitions regarding various bodily sensations are supposed to play only a consequential role. Compared with the Type II and Type III panic attacks, the probability and intensity of experiencing the remaining symptoms of the $D S M-I I I-R$ classification are highest.

In the hyperventilation theory of (classic) panic attacks (Ley, 1991), dyspnea is primarily conceived as the consequence of hyperventilatory hypocapnia. Recent studies also investigated dyspnea and dyspnea-fear as a result of chronic pulmonary obstruction (Carr, Lehrer \& Hochron, 1992; Porzelius, Vest \& Nochomovitz, 1992; Carr, Lehrer, Rausch \& Hochron, 1994). The results of these studies suggest that dyspnea may only play a consequential role in panic. Carr et al. (1992) observed that in contrast to asthmatics, panic symptoms in panic disorder (PD) patients are not mediated primarily by dyspnea but by catastrophic interpretations of sensations associated with normal pulmonary functioning. Porzelius et al. (1992) have found that panic symptoms in patients with chronic obstructive pulmonary disease are associated with the occurrence of catastrophic cognitions, and not with the degree of respiratory impairment. Recently, Carr et al. (1994) reported that anxiety sensitivity, but not pulmonary function, was related to panic disorder in individuals with asthma.

Asmundson and Stein (1994) further investigated the relationship between dyspnea, pulmonary function and panic symptoms in PD patients. In 15 PD patients without significant impairments in pulmonary function, supportive evidence for Ley's theory of dyspneic panic was found. PD patients with low FEF $50 \%$ scores, a sensitive indicator of obstructive lung disease, were found to be characterized by significantly lower $\mathrm{FEV} / \mathrm{FVC}$ ratios, a more specific measure of airway obstruction. Additionally, the PD patients with low FEF 50\% scores reported having experienced a greater number and severity of panic symptoms, including respiratory and cognitive symptoms, than did patients with higher FEF $50 \%$ scores. The authors suggest that a pulmonary obstructive component in the low FEF $50 \%$ subgroup, although not pathological, leads to the experience of 'air hunger' and greater respiratory drive, which, in turn, leads to dyspneic fear and, ultimately, panic.

The present study was designed in order to further extend the study of Asmundson and Stein (1994) in a larger number of PD patients using identical measures for pulmonary function and equivalent and more extensive psychological measures for panic and associated psychopathology.

Selection of subjects

METHOD

Data were collected from PD patients of the University Psychiatric Outpatient Clinic, Leiden, participating in a comparative outcome study in PD. The present data were obtained before the start of the outcome study. Patients had to

*Author for correspondence. 
meet the following inclusion criteria: (a) a primary diagnosis of PD according to $D S M-I I I-R$ criteria (American Psychiatric Association, 1987) as assessed with the Anxiety Disorders Interview Schedule (ADIS-R; DiNardo, O'Brien, Barlow, Waddell \& Blanchard, 1983; De Ruiter, 1987); (b) age between 18 and $60 \mathrm{yr}$; and (c) informed consent obtained after the study has been fully described. In addition, the following exclusion criteria were used: (a) suffering from one of the following somatic disorders: hyperthyreodism, pheochromocytome, bronchial asthma with medication use or angina pectoris; (b) pregnancy; (c) alcohol or drug abuse or dependence; (d) current psychosis or major depression; and (e) problems with speaking Dutch.

\section{Assessment}

Physiological measures. Pulmonary function was measured according to standardization recommendations (Quanjer, Tammeling, Cotes, Pedersen \& Peslin, 1993) using a rolling-real spirometer (Mijnhardt Volugraph). The following indices of pulmonary function were assessed: (a) Forced Vital Capacity (FVC); (b) Forced Expiratory Volume in one second (FEV $)$; (c) Peak Expiratory Flow (PEF); (d) Forced Expiratory Flow at 50\% of forced vital capacity (FEF 50\%); and (e) the ratio of $\mathrm{FEV}_{1}$ to $\mathrm{FVC}$ (FEV $/ F V C$ ). With the exception of the $\mathrm{FEV}_{1} / \mathrm{FVC}$ ratio, all indices were based on the percent predicted values derived from height, age and gender (Quanjer et al., 1993).

Psychological measures. Panic Questionnaire (PQ). This questionnaire asks patients to rate the severity of 13 primarily somatic symptoms using a Likert-type 4-point scale ranging from 'not at all' to 'very much' (range 0-3). The 13 symptoms correspond to the 13 symptoms mentioned in the $D S M-I I I-R$ criteria for PD. Patients rated the severity of symptoms occurring during the most severe panic attack of the last two weeks. A subscale of respiratory symptoms (dyspnea, choking, dizziness, trembling, paresthesias) and cognitive symptoms (fear of dying/fear of going crazy or losing control) was derived from the PQ. A total severity score for panic symptoms and specific respiratory and cognitive symptoms was calculated by summing up the PQ distress scores and dividing them by the number of items in order to make them comparable. Moreover, a score for percentage endorsed symptoms was derived by calculating the percentage of endorsed PQ scores, recoded as ' 0 ' $(0,1)$ and ' $l$ ' $(2,3)$.

Panic Attack Diary (PAD). Patients kept a daily record of panic attacks. As a reminder, on each sheet panic attacks were defined "as intense anxiety which comes on suddenly accompanied by severe bodily sensations (followed by the 11 somatic symptoms mentioned in the $D S M-I I I-R$ criteria for a panic attack). The form for panic attacks consisted of the following columns: date, time, duration (in minutes), intensity [rated on a Likert-type 11 -point scale ranging from 'no anxiety at all' to 'strongest anxiety ever experienced' (range 0-10)], and situation. In the analyses, panic attack frequency and mean panic intensity during the two weeks before the pulmonary assessment will be reported.

State-Trait Anxiety Inventory (STAI) (Speilberger, Gorsuch \& Lushene, 1970; Van der Ploeg, Defares \& Spielberger, 1979). Patients rated their general level of anxiety and the anxiety which had occurred during the most severe panic attack of the last two weeks.

Watson and Marks Scale (WMS) (Watson \& Marks, 1971). On this slightly modified version of the original WMS, patients rated their level of anxiety and agoraphobic avoidance in five standard situations (Emmelkamp, 1979). Ratings were made on a Likert-type 9-point scale (range 0-8). A single rating for both anxiety and avoidance was calculated by summing up the item scores.

Self-Rating Depression Scale (SDS) (Zung, 1965; Dijkstra, 1974). This measure was used to assess the level of depression.

\section{Procedure}

At a first assessment session patients completed the PQ, STAI, WMS and SDS. Patients were instructed in using the PAD for self-monitoring of their panic attacks during the coming two weeks. Patients were instructed to remain medication-free for $24 \mathrm{hr}$ prior to the pulmonary function testing in the outpatient Lung Function Laboratory of the University Hospital Leiden two weeks later. After they had been informed about the nature of the spirometry equipment, patients were asked to perform three forced vital capacity manoeuvres, from which the highest values were used in the analyses (Quanjer $e t$ al., 1993).

\section{Statistical analyses}

As in the study of Asmundson and Stein (1994), data were analyzed in a series of univariate as opposed to multivariate analysis of variance. First, following Asmundson and Stein (1994), patients were divided into two groups by taking a median split of FEF $50 \%$ scores. Secondly, between group differences in biographical and medical status variables, physiological and psychological measurements were analyzed using univariate analysis of variance in case of continuous variables and chi-square analyses in case of measurement on a nominal level.

Because the formation of two subgroups by taking a median split of FEF $50 \%$ scores is arbitrarily and not clinically validated, also Pearson product-moment correlation coefficients between FEF $50 \%$ scores and $\mathrm{FEV}_{1} / \mathrm{FVC}$ ratios on the one hand and measurements of panic and associated psychopathology on the other were calculated.

In contrast to the study of Asmundson and Stein (1994), also PD patients smoking in excess of a half pack of cigarettes per day were included, and a substantially higher amount of patients used low maintenance doses of benzodiazepines. In order to analyze whether use of cigarettes or benzodiazepines could be regarded as a confounding variable, the association between use of cigarettes or benzodiazepines with both pulmonary and psychological measurements was analyzed separately using univariate analyses of variance.

\section{Subjects}

\section{RESULTS}

The sample consisted of 38 patients (19 men, 19 women). Mean age was 36.8 yr (SD 8.2, range 21-58). The median duration of panic attacks was 37.5 months (range 3-276). None of the patients used antidepressants and 19 patients were on low maintenance doses of benzodiazepines for extended periods of time. Twelve patients did not smoke, 7 patients were smoking less than a half pack of cigarettes per day, and 19 were smoking in excess of a half pack of cigarettes per day.

Differences between patients with high and low FEF $50 \%$ scores

Patients were divided taking a median split of FEF $50 \%$ predicted values (median $=103$ ). In the 19 low FEF $50 \%$ patients the range of the percent predicted FEF $50 \%$ values was 39 to 103 and in the 19 high FEF $50 \%$ patients 104 to 179 . In 
Table 1. Means, standard deviations, and analyses of variance results for physiological measures

\begin{tabular}{|c|c|c|c|c|c|c|}
\hline \multirow[b]{2}{*}{ Measure } & \multicolumn{2}{|c|}{$\begin{array}{c}\text { Low FEF } 50 \% \\
\text { PD patients }(N=19)\end{array}$} & \multicolumn{2}{|c|}{$\begin{array}{c}\text { High FEF } 50 \% \\
\text { PD patients }(N=19)\end{array}$} & \multirow[b]{2}{*}{$F$} & \multirow[b]{2}{*}{$P$} \\
\hline & Means & SD & Means & SD & & \\
\hline FVC & 103.9 & 13.5 & 104.9 & 11.8 & 0.06 & 0.811 \\
\hline FEV, & 96.1 & 12.1 & 108.2 & 8.8 & 12.34 & 0.001 \\
\hline PEF & 79.3 & 15.7 & 102.0 & 17.0 & 18.31 & 0.000 \\
\hline $\mathrm{FEV}_{1} / \mathrm{FVC}$ & 0.788 & 0.080 & 0.874 & 0.050 & 15.61 & 0.000 \\
\hline
\end{tabular}

Note: FVC = Forced Vital Capacity; $\mathrm{FEV}_{1}=$ Forced Expiratory Volume in one second; PEF $=$ Peak Expiratory Flow; FEV $/$ FVC = the ratio of FEV 1 to FVC. All measures, except FEV $/ F V C$, are represented as percent predicted values based on height, age and gender.

Table 2. Means, standard deviations, and analyses of variance results for psychological measures

\begin{tabular}{|c|c|c|c|c|c|c|}
\hline \multirow[b]{2}{*}{ Measure } & \multicolumn{2}{|c|}{$\begin{array}{c}\text { Low FEF } 50 \% \\
\text { PD patients }(N=19)\end{array}$} & \multicolumn{2}{|c|}{$\begin{array}{c}\text { High FEF } 50 \% \\
\text { PD patients }(N=19)\end{array}$} & \multirow[b]{2}{*}{$F$} & \multirow[b]{2}{*}{$P$} \\
\hline & Means & SD & Means & SD & & \\
\hline Global symptom severity* & 1.3 & 0.6 & 1.3 & 0.6 & 0.00 & 0.96 \\
\hline Severity respiratory symptoms* & 1.4 & 0.6 & 1.4 & 0.5 & 0.00 & 1.00 \\
\hline Severity cognitive symptoms* & 0.8 & 0.7 & 1.0 & 0.8 & 0.41 & 0.53 \\
\hline$\%$ Endorsed symptoms* & 40 & 25 & 40 & 25 & 0.00 & 0.96 \\
\hline Past 2-week panic frequency $†$ & 13.6 & 11.0 & 13.7 & 9.9 & 0.00 & 0.97 \\
\hline Past 2-week mean panic intensity $\dagger$ & 3.8 & 2.0 & 4.4 & 1.3 & 1.14 & 0.29 \\
\hline STAI-State & 60.7 & 9.5 & 62.6 & 9.0 & 0.38 & 0.54 \\
\hline STAI-Trait & 54.0 & 6.8 & 52.7 & 8.7 & 0.29 & 0.59 \\
\hline WMS anxiety & 17.4 & 8.7 & 18.8 & 8.4 & 0.26 & 0.61 \\
\hline WMS avoidance & 23.7 & 11.4 & 24.4 & 9.3 & 0.04 & 0.84 \\
\hline SDS & 47.9 & 8.2 & 47.4 & 7.4 & 0.03 & 0.85 \\
\hline
\end{tabular}

Note: STAI = State-Trait Anxiety Inventory; WMS = Watson and Marks Scale; SDS = Self-Rating Depression Scale; ${ }^{*}$ scores derived from the Panic Questionnaire; $\nmid$ : scores derived from the Panic Attack Diary.

Table 3. Pearson product-moment correlation coefficients between FEF-scores and psychological measures

\begin{tabular}{lccccccccrrr}
\hline Measure & I & II & III & IV & V & VI & VII & VIII & IX & X & XI \\
\hline FEF & -0.08 & -0.11 & 0.12 & -0.05 & -0.11 & 0.18 & 0.16 & -0.01 & -0.13 & -0.07 & -0.08 \\
FEV $/$ FVC & -0.09 & -0.08 & 0.01 & -0.03 & -0.17 & 0.22 & 0.07 & 0.14 & 0.04 & 0.17 & 0.13 \\
\hline
\end{tabular}

Note: I = Global symptom severity*; II = Severity respiratory symptoms $*$ III = Severity cognitive symptoms*; IV $=\%$ endorsed symptoms*; $\mathrm{V}=$ Past 2-week panic frequencyt; VI = Past 2-week mean panic intensityt; VII = State-Trait Anxiety Inventory (STAI): state subscale; VIII = STAI: trait subscale; IX = Watson and Marks Scale (WMS): anxiety; $X=$ WMS: avoidance; XI $=$ Self-Rating Depression Scale. *Scores derived from the Panic Questionnaire; + Scores derived from the Panic Diary.

analyzing differences between low and high FEF $50 \%$ patients in age, sex, duration of complaints, cigarette use and use of benzodiazepines no significant differences emerged. Differences in spirometric measurements between high and low FEF $50 \%$ patients can be found in Table 1 . In comparison to high FEF $50 \%$ patients, low FEF $50 \%$ patients demonstrated significantly lower percent predicted values for $\operatorname{FEV}_{1}[F(1,36)=12.34, P<0.001]$ and $\operatorname{PEF}[F(1,36)=18.31, P<0.001]$, as well as significantly lower $\mathrm{FEV}_{1} / \mathrm{FVC}$ ratios $[F(1,36)=15.61, P<0.001]$. Mean percent predicted values for FVC did not differ significantly between groups.

Mean values for the psychological measurements are presented in Table 2. As can be inferred from this table, none of the between group differences proved to be significant.

Also, none of the correlations between FEF $50 \%$ scores and $\mathrm{FEV}_{1} / \mathrm{FVC}$ ratios on the one hand and measurements for panic and concomitant psychopathology on the other approached the level of significance (see Table 3).

\section{Use of cigarettes and benzodiazepines as a possible confounder}

In contrast to patients smoking 10 or less cigarettes per day, patients smoking in excess of a half pack of cigarettes per day showed significantly lower scores for $\mathrm{FVC}[F(1,36)=5.53, P<0.05], \mathrm{FEV}_{1}[F(1,36)=13.10, P<0.001]$, and PEF $[F(1,36)=7.23, P<0.05]$. Mean $F E V_{1} / F V C$ and FEF values did not differ significantly between groups. However, none of the differences between low and high smokers on any of the psychological measurements proved to be significant. Also, both in the group of low and high smokers no significant differences between low and high FEF $50 \%$ patients (median FEF $50 \%$ of resp. 105.6 and 93.6) on any of the psychological measurements were observed.

Use of benzodiazepines (yes vs no) did not manifest a significant relationship with either spirometry or psychological measurements.

\section{DISCUSSION}

The purpose of this study was to further extend the study of Asmundson and Stein (1994), who reported that a subgroup of PD patients representing early signs of obstructive lung disease experienced panic attacks characterized by severe respiratory and cognitive/fear symptoms to a greater extent than PD patients with no evidence of airway obstruction. The present study failed to replicate these findings notwithstanding its greater power to detect significant differences due to the inclusion of a greater number of PD patients. Although patients with low FEF $50 \%$ scores differed from patients with high FEF $50 \%$ on several pulmonary indices, no significant differences in panic symptomatology or concomitant psychopathology were observed. Also, FEF $50 \%$ scores (a sensitive indicator of obstructive lung disease) and FEV / FVC 
ratios (a more specific measure of airway obstruction) were not associated with any of the psychological measurements for symptom severity.

These divergent findings cannot be attributed to a lack of early signs of obstructive lung disease in the present sample. Asmundson and Stein (1994) found that in comparison to high FEF 50\% patients, low FEF $50 \%$ patients were characterized by a significantly lower $\mathrm{FEV}_{1} / \mathrm{FVC}$ ratio, while a trend toward a significant difference for the $\mathrm{FEV}$, measure was observed. In the present study the significant difference between high and low FEF $50 \%$ patients for $\mathrm{FEV}_{1} / \mathrm{FVC}$ was replicated, but also significant differences for $\mathrm{FEV}_{1}$ and PEF were found. Moreover, in the present study the actual differences on these measures between high and low FEF $50 \%$ patients were of a greater magnitude in comparison to the study of Asmundson and Stein (1994).

Differences between study results may be related to differences in the assessment of panic symptomatology and concomitant psychopathology. The only significant differences reported by Asmundson and Stein (1994) were found on the unpublished Anxiety Symptom Questionnaire (ASQ), a 20-item questionnaire that retrospectively assesses symptoms and symptom severity during periods of anxiety and panic (Stein, 1992). In the present study measurements for the same variables as assessed with the ASQ were obtained by both a retrospective assessment of the most severe panic attack of the last two weeks (PQ) and a daily record of panic attacks (PAD). However, it seems unlikely that both the self-monitoring data and retrospective ratings in the present study assess different variables than the retrospective ratings obtained by the ASQ. Consequently, it seems unlikely that the failure to replicate the study results of Asmundson and Stein (1994) is related to differences in the psychological measures used.

Furthermore, in contrast to the study of Asmundson and Stein (1994) we included patients smoking in excess of a half pack of cigarettes per day and a substantially higher amount of patients using low maintenance doses of benzodiazepines. However, our study results did not indicate that use of cigarettes or benzodiazepines could be regarded as variables confounding the relationship between pulmonary function and panic symptomatology.

In conclusion, the results of the present study are not in accordance with the hypothesis consistent with the dyspnea-fear theory of panic, that there may exist a distinct subgroup of panic patients with early signs of actual airway obstruction leading to uncontrollable dyspnea and fear of suffocation. Asmundson and Stein (1994) also stressed that there is no information which suggest that PD patients are prone to develop chronic obstructive pulmonary disease (COPD) in later life. The explorative findings of the above authors in a sample of only 15 PD patients related to a possible relationship between pulmonary function and panic symptomatology possibly represent a chance finding. In the absence of further comfirmatory evidence for this relationship, consideration of the efficacy bronchodilators in PD patients with lower FEF $50 \%$ scores and associated respiratory complaints may be conceptualized as therapeutic suggestions for a placebo treatment unrelated to specific pathogenetic mechanisms involved in the occurrence of panic.

\section{REFERENCES}

American Psychiatric Association (1987). Diagnostic and statistical manual of mental disorders (3rd Edn, revised) Washington, DC: Author.

Asmundson, G. J. G. \& Stein, M. B. (1994). A preliminary analysis of pulmonary function in panic disorder: Implications for the dyspnea-fear theory. Journal of Anxiety Disorders, 8, 63-70.

Carr, R. E., Lehrer, P. M. \& Hochron, S. M. (1992). Panic symptoms in asthma and panic disorder: A preliminary test of the dyspnea-fear theory. Behaviour Research and Therapy, 30, 251-261.

Carr, R. E., Lehrer, P. M., Rausch, L. L. \& Hochron, S. M. (1994). Anxiety sensitivity and panic attacks in an asthmatic population. Behaviour Research and Therapy, 32, 411-418.

Clark, D. (1986). A cognitive approach to panic. Behaviour Research and Therapy, 14, 461-470.

De Ruiter, C. (1987). Nederlandse bewerking van het Anxiety Disorder Interview Schedule-revised (ADIS-R). Utrecht: Vakgroep Psychiatrie RUU.

Dijkstra, P. (1974). De zelfbeoordelingsschaal voor depressie van Zung. In Praag, H. M. \& Rooymans, H. G. M. (Eds), Stemming en ontstemming. Theorie en praktijk bij de diagnostiek en behandeling van depressie (pp. 98-120). Amsterdam: De Erven Bohn.

Di Nardo, P. A., O'Brien, G. T., Barlow, D. H., Waddell, M. T. \& Blanchard, E. B. (1983). Reliability of $D S M-I I I$ anxiety disorder categories using a new structured interview. Archives of General Psychiatry, 40, 1070-1074.

Emmelkamp, P. M. G. (1979). The behavioral study of clinical phobias. In Hersen, M., Eisler, R. M. \& Miller, P. M. (Eds), Progress in behavior modification, Vol. 8 (pp. 55-126). New York: Academic Press.

Ley, R. (1991). The efficacy of breathing retraining and the centrality of hyperventilation in panic disorder: A reinterpretation of experimental findings. Behaviour Research and Therapy, 29, 301-304.

Ley, R. (1992). The many faces of pan: Psychological and physiological differences among three types of panic attacks. Behaviour Research and Therapy, 30, 347-357.

Porzelius, J., Vest, M. \& Nochomovitz, M. (1992). Respiratory function, cognitions, and panic in chronic obstructive pulmonary patients. Behaviour Research and Therapy, 30, 75-77.

Quanjer, Ph. H., Tammeling, G. J., Cotes, J. E., Pedersen, O. F. \& Peslin, R. (1993). Lung volumes and forced expiratory flows. European Respiratory Journal (Suppl. 16), 6, 4-39.

Spielberger, C. D., Gorsuch, A. \& Lushene, R. L. (1970). The State-Trait Anxiety Inventory. Palo Alto, Calif.: Consulting Psychologist Press.

Stein, M. B. (1992). Anxiety Sensations Questionnaire. Unpublished scale: University of Manitoba.

Van der Ploeg, H. M., Defares, P. B. \& Spielberger, C. D. (1980). Handleiding bij de Zelf-Beoordelings Vragenlijst (ZBV). Lisse: Swets \& Zeitlinger.

Watson, J. P. \& Marks, I. M. (1971). Relevant and irrelevant fear in flooding. A crossover study of phobic patients. Behaviour Therapy, 2, 275-293.

Zung (1965). A self-rating depression scale. Archives of General Psychiatry, 12, 63-70. 